\title{
Gene silencing of translationally controlled tumor protein (TCTP) by siRNA inhibits cell growth and induces apoptosis of human prostate cancer cells
}

\author{
MUNIRATHINAM GNANASEKAR, SIVASAKTHIVEL THIRUGNANAM, GUOXING ZHENG, \\ AOSHUANG CHEN and KALYANASUNDARAM RAMASWAMY
}

\author{
Department of Biomedical Sciences, University of Illinois, College of Medicine, Rockford, IL 61107, USA
}

Received November 24, 2008; Accepted January 12, 2009

DOI: 10.3892/ijo_00000252

\begin{abstract}
Translationally controlled tumor protein (TCTP) is a novel anti apoptotic protein which is highly expressed in several cancer cell types including prostate cancer. However, studies investigating the role of TCTP in prostate cancer are scarce. Therefore, in this study we evaluated the effect of small interference RNA (siRNA) based knocking down of TCTP gene in prostate cancer cells. Cell proliferation and apoptosis were evaluated. Our results showed that TCTP is highly expressed in LNCaP cells compared to normal prostate epithelial cells. Transfection with TCTP siRNA specifically and drastically reduced the expression of both mRNA and protein levels of TCTP in LNCaP cells. The decreased expression of TCTP was associated with decreased viability of LNCaP cells. Further analysis of the transfected LNCaP cells showed that they undergo apoptosis via caspase- 8 and caspase-3 dependent pathways. Results presented herein suggest a potential therapeutic application for prostate cancer by targeting TCTP gene using an siRNA approach.
\end{abstract}

\section{Introduction}

Translationally controlled tumor protein (TCTP), originally identified in Ehrlich ascites tumor cell line (1), is a growthassociated protein ubiquitously present in a wide variety of organisms from yeast to mammals $(2,3)$. TCTP is an antiapoptotic protein (4) that is highly expressed in several cancer cells including prostate tumors $(5,6)$. Subsequent studies showed that TCTP is a potential target for tumor reversion (7). Expression of TCTP is up-regulated by various stimulus including dioxin (8), heavy metals (9), growth factors (10), and Vitamin D (11). TCTP gene is significantly downregulated in tumor revertant cells (5) and it was suggested that inhibiting the expression of TCTP could revert the cancer cells into normal phenotypes. Although TCTP expression

Correspondence to: Dr Munirathinam Gnanasekar, Department of Biomedical Sciences, University of Illinois, College of Medicine, 1601 Parkview Ave., Rockford, IL 61107, USA

E-mail:mgnanas@uic.edu

Key words: translationally controlled tumor protein, $\mathrm{LNCaP}$, prostate cancer, siRNA is elevated in prostate cancer the role of TCTP in prostate carcinogenesis is not fully understood.

TCTP is a calcium-binding $(12,13)$ and tubulin binding protein $(14,15)$. Serial analysis of gene expression (SAGE) analysis showed that TCTP is the most highly expressed protein in prostate cancer cells compared to other calcium binding proteins (CBPs) (6). Interestingly, we now know that CBPs play a crucial role in prostate cancer progression and tumorigenesis $(16,17)$ and depletion of CBP induces apoptosis in prostate cancer cells (18). The role of CBPs in buffering intracellular calcium levels and its protection against apoptosis is well studied in prostate cancer (19). Similarly, it is well established that cells can undergo apoptosis when intracellular calcium levels are up-regulated (20). Therefore, being the most highly expressed CBP in prostate cancer, TCTP may have an important role in calcium homeostasis and in the survival of prostate cancer cells.

Prostate cancer is one of the leading causes of cancerrelated death in men next to lung cancer in the Western world. About $15-16 \%$ of men will have prostate cancer during their life span and approximately $3 \%$ of men will die due to this cancer. Current treatment options are unsatisfactory and newer agents for the management of prostate cancer are urgently needed. Small interference RNA (siRNA) is a rapidly developing new technology that functions by interfering in the transcription of a specific gene within the cell, so called knock down of the gene expression. siRNA technology is successfully used to knockdown several genes within a cell and is being developed as a novel therapeutic approach for a variety of genetic disorders (21). Prostate cancer is a complex disease in which the initial stages of prostate cancer is dependent on the hormone, androgen and subsequent emergence of hormone resistant cancer at the later stages. LNCaP cells which represent androgen-dependent prostate cancer that can be cultured in vitro is widely used to evaluate the anticancer potential of various drugs, including siRNA (22). Therefore, the present study was undertaken to evaluate the anticancer potential of siRNA targeting TCTP in LNCaP prostate cancer cells.

\section{Materials and methods}

Culturing of prostate cells. Human lymph node prostate cancer cells (LNCaP) and normal prostate epithelial cells 
(RWPE-1) were obtained from ATCC (Manassas, VA). Cells were cultured in either $25 \mathrm{~cm}^{2}$ tissue culture flask, 6-well, 96-well or tissue culture glass slides at $37^{\circ} \mathrm{C}$ in $5 \% \mathrm{CO}_{2}$ environment. LNCaP cells were cultured in RPMI-1640 medium with $10 \%$ fetal bovine serum (FBS). RWPE-1 cells were grown in keratinocyte serum-free medium (K-SFM) (Invitrogen Technologies, Carlsbad, CA) supplemented with bovine pituitary extract $(0.05 \mathrm{mg} / \mathrm{ml})$ and epidermal growth factor $(5 \mathrm{ng} / \mathrm{ml})$.

Small interfering RNA (siRNA) gene silencing assay. The siRNAs of TCTP and lamin A/C were synthesized at Dharmacon Research Inc. (Lafayette, CO). The target sequence of TCTP (23) used for designing siRNA was from nucleotide 121-141 (5'-AAGGTAACATTGATGACTCGC-3'. Sense siRNA, 5'-GGUAACAUUGAUGACUCGCdTdT-3'; antisense siRNA, 5'-GCGAGUCAUCAAUGUUACCdTdT-3'). For lamin $\mathrm{A} / \mathrm{C}$ the target sequence (cDNA) was 5'-CTGG ACTTCCAGAAGAACA-3'. Sense SiRNA, 5'-CUGGACU UCCAGAAGAACAdTdT-3'; antisense siRNA, 3'-dTdT GACCUGAAGGUCUUCUUGU-5'. All procedures were performed under RNAse free environment, using RNAse-free water. Approximately, $10^{4} \mathrm{LNCaP}$ cells were then transfected with a final concentration of $100 \mathrm{nM}$ of siRNA duplexes using lipofectamine reagent (Invitrogen). Twentyfour, forty-eight and seventy-two hours after the transfection, cells were collected and used for cell viability and fluorescence microscopy studies and RT-PCR analysis, Western blot analysis.

RT-PCR analysis of TCTP. mRNA was isolated from mock transfected and TCTP- siRNA transfected LNCaP cells using TRIzol reagent according to the manufacturer's instructions (Invitrogen). The mRNA was then converted to cDNA using an RT-PCR kit purchased from Ambion. Expression of TCTP in the cDNA samples were determined by PCR using gene specific TCTP primers (forward primer 5'-CCCAAGCTTAT GATTATCTACCGGGACCTC-3'; reverse primer 5'-CGCG GATCCTTAACATTTTTCCATTTTTAA-3') designed from IDT (Coralville, Iowa). PCR parameters were $95^{\circ} \mathrm{C}$ of denaturation for $30 \mathrm{sec}, 55^{\circ} \mathrm{C}$ of primer annealing for $30 \mathrm{sec}$, $72^{\circ} \mathrm{C}$ of primer extension for $30 \mathrm{sec}$ and the cycle was repeated for 30 times. A final extension of $5 \mathrm{~min}$ was performed at $72^{\circ} \mathrm{C}$ before storing the samples at $4^{\circ} \mathrm{C}$. Following PCR, the products were analyzed on a $1 \%$ agarose gel electrophoresis.

Western blot analysis. Mock transfected and TCTP-siRNA transfected LNCaP cells were lysed by cell lysis buffer and protein concentration in the soluble fractions were determined by Pierce BCA protein assay kit. The proteins were then resolved on $12 \%$ SDS-PAGE and transferred to nitrocellulose membrane. After blocking the non-specific sites with $5 \%$ skimmed milk solution for $1 \mathrm{~h}$ at room temperature, membranes were washed with wash buffer (TBS containing $0.05 \%$ Tween-20) for 5 times and incubated with rabbit antiTCTP antibodies (1:1000; MBL, Woburn, MA) for $1 \mathrm{~h}$ at room temperature. After washing the membranes were incubated with HRP labeled goat anti-rabbit antibodies (1:5000) for $1 \mathrm{~h}$ at room temperature. Following incubation, the membrane was washed and the reactive bands were detected using ECL chemiluminescence substrate (Amersham, Piscataway, NJ).

Cell viability assay. LNCaP cells $\left(2 \times 10^{3}\right.$ cells $\left./ \mathrm{ml}\right)$ were cultured in 96-well tissue culture plates until they reached $50 \%$ confluency. Cells were then transfected with a final concentration of $100 \mathrm{nM}$ TCTP siRNA or Lamin A/C siRNA. 24,48 and $72 \mathrm{~h}$ after siRNA transfection, viability of the cells were determined by a cell counting kit-8 (CCK-8) purchased from Dojindo Molecular Technologies (Gaithersburg, MA). Briefly, $10 \mu 1$ of water soluble formazan dye was added to the mock transfected and siRNA transfected cells and plates were incubated for $2 \mathrm{~h}$ in $5 \% \mathrm{CO}_{2}$. Color developed was measured at $450 \mathrm{~nm}$ using an ELISA plate reader.

Trypan-blue exclusion to determine cell viability. LNCaP cells were cultured in eight chamber polystyrene vessel tissue culture treated glass slides (Becton-Dickinson, Franklin Lakes, $\mathrm{NJ}$ ). When the culture reached $50 \%$ confluency, cells were transfected with $100 \mathrm{nM}$ of TCTP siRNA. Untreated or cells transfected with lamin siRNA served as controls. Following transfection, cells were further cultured for 24, 48 and $72 \mathrm{~h}$. At each time-point $100 \mu 1$ of trypan-blue dye (Sigma, St. Louis, MO) was added to cell samples and viability determined under a light microscope by counting cells that have excluded the dye.

Annexin $V$ and propidium iodide staining to determine apoptosis. LNCaP cells undergoing apoptosis were detected by Annexin V-FITC apoptosis detection kit purchased from MBL Inc. Briefly, LNCaP cells cultured in tissue culture glass slides were transfected with $100 \mathrm{nM}$ of TCTP siRNA for 24, 48 and $72 \mathrm{~h}$. Following siRNA transfection, the cells were washed with RPMI-medium, $1 \mathrm{X}$ binding buffer was added to the adherent cells. After addition of binding buffer, $5 \mu \mathrm{l}$ of Annexin V-FITC and propidium iodide (PI) were added to the cell cultures and further incubated at room temperature for $5 \mathrm{~min}$ in the dark. Following incubation, fluorescent cells were counted under a fluorescence microscope.

Caspase activity. Caspase- 3 and caspase- 8 activities were measured using colorimetric assay kits (R\&D Systems, Minneapolis, MN). After transfection with TCTP siRNA, cells were washed with ice-cold PBS and caspase- 3 and caspase- 8 activities were determined. Caspase colorimetric substrates DEVD-pNA (Caspase-3) or IETD-pNA (Caspase-8) were added to the cell lysate and assays were performed in a $100-\mu 1$ volume in $96-$-well flat-bottomed plates. Chromophore p-nitroanilide is released as a result of cleavage of substrates by caspase activity. The caspase enzymatic activity in the cell lysate is directly proportional to the chromophore formation, which was quantified spectrophotometrically at a wavelength of $405 \mathrm{~nm}$ using a microplate reader. Data were corrected for the background values that had no substrate or no cell lysate added.

Statistical analysis. Statistical analysis was performed using a Mann-Whitney U rank sum tests using Sigmastat 2.0 (Jandel 


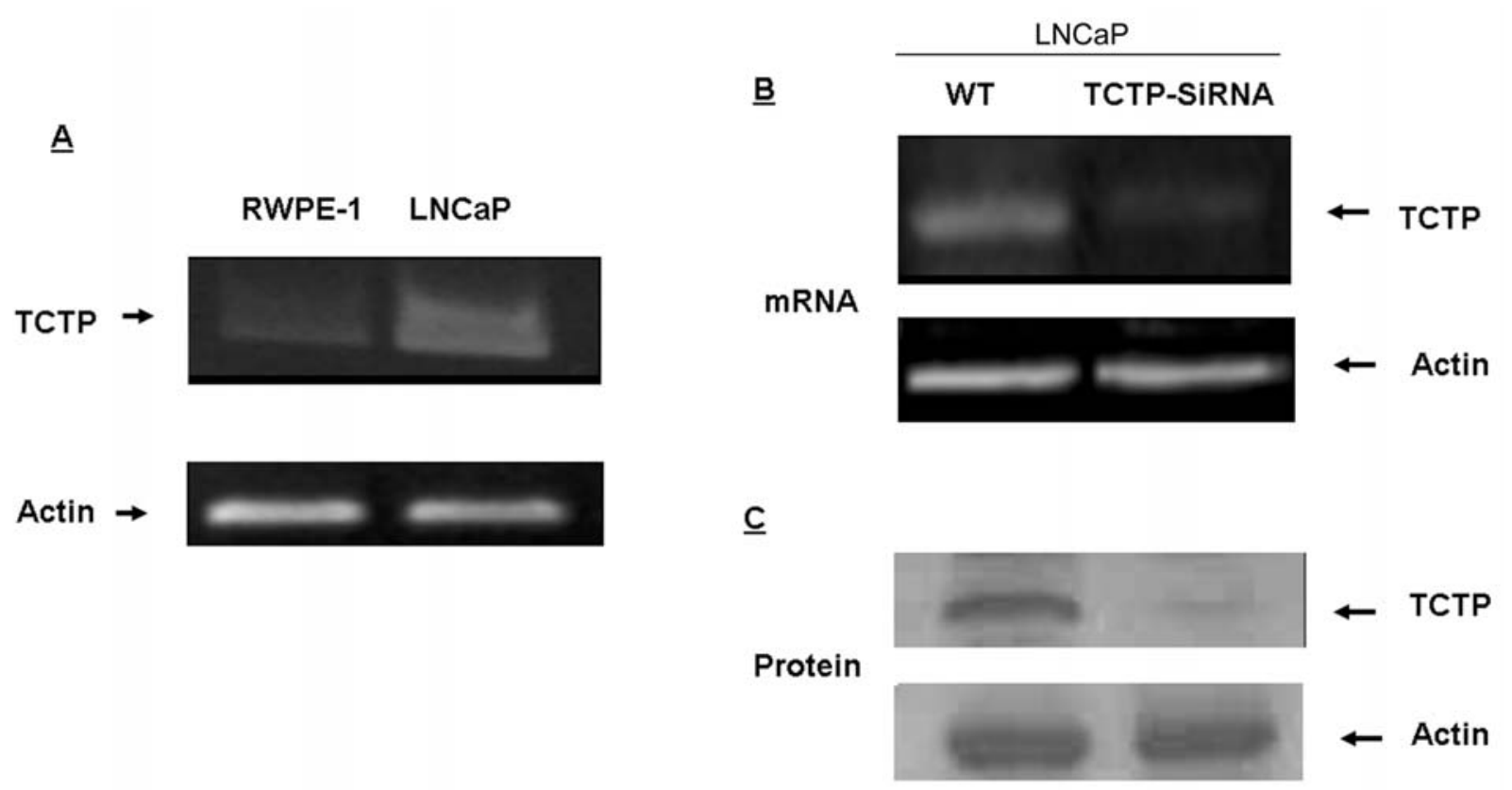

Figure 1. Gene silencing of TCTP by siRNA transfection. (A) Expression analysis of TCTP in normal (RWPE-1) and prostate cancer cells (LNCaP). mRNA extracted from normal and prostate cancer cells were used to amplify TCTP gene by PCR. Agarose gel electrophoresis shows that TCTP is highly expressed in prostate cancer cells compared to normal cells. (B) LNCaP cells $\left(10^{4}\right.$ cells $\left./ \mathrm{ml}\right)$ were transfected with TCTP-siRNA using lipofectamine. After $72 \mathrm{~h}$ of transfection, the cells were collected and the expression of TCTP was analyzed by RT-PCR. Non-transfected cells served as control. Results show that expression of TCTP gene is silenced by siRNA transfection. (C) Similarly, the transfected and non-transfected cells were analyzed for TCTP protein expression. Western blot analysis showed that LNCaP cells transfected with TCTP siRNA drastically down-regulated the expression of TCTP protein. Data are representative of one of three similar experiments.

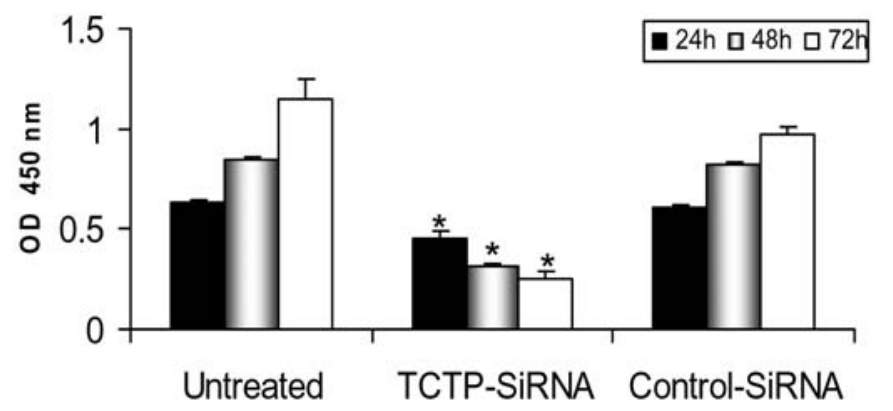

Figure 2. TCTP siRNA transfection blocks the growth of prostate cancer cells. Approximately, $2 \times 10^{3} \mathrm{LNCaP}$ cells/ml were cultured in 96 -well tissue culture plates and transfected with TCTP siRNA and control lamin siRNA. The viability of both transfected and non-transfected cells at various timepoints were analyzed by adding $10 \mu 1$ of formazan dye. Intensity of the color developed was measured in an ELISA plate reader at an optical density of $450 \mathrm{~nm}$. Results show that knock down of TCTP gene expression significantly decreases the proliferation of prostate cancer cells compared to the nontransfected and control lamin siRNA treated cells. ${ }^{*} \mathrm{P}<0.05$ statistically significant compared to control.

Scientific Software, San Rafael, CA). P $<0.05$ was considered statistically significant.

\section{Results}

Gene silencing effects of TCTP in LNCaP cells. Expression of TCTP in LNCaP and RWPE-1 cells were first determined by RT-PCR. Results (Fig. 1A) showed that TCTP is highly expressed in LNCaP prostate cancer cells compared to RWPE-1 normal prostate epithelial cells. Cells were then transfected with TCTP-siRNA and consequent gene silencing was confirmed by RT-PCR. Time course analysis showed that $72 \mathrm{~h}$ after transfection with TCTP siRNA, there was a significant decrease in the TCTP mRNA transcript in transfected cells. This was further confirmed by Western blot analysis (Fig. 1C) that also showed decreased TCTP protein levels in transfected cells. This TCTP gene silencing effect was reproducible and was specific in that it failed to knock down the expression of an unrelated protein, $\beta$-actin (Fig. 1B).

Effects of TCTP gene silencing on the viability of LNCaP cells. Following knock down of TCTP gene with siRNA, we also measured the cell viability in TCTP-siRNA transfected LNCaP cells by trypan-blue staining and CCK- 8 assay. These studies showed that knocking down of TCTP gene resulted in decreased cell proliferation (Fig. 2) and low cell viability in LNCaP cells (Fig. 3) compared to cells that were transfected with a control siRNA.

Detection of apoptosis by Annexin-V FITC staining. We then analyzed whether reduction in cell viability was due to cell death and if so whether they are undergoing apoptosis. LNCaP cells transfected with TCTP siRNA and control siRNA were stained with Annexin V-FITC and propidium iodide. Stained cells were visualized under a fluorescence microscope. Results showed that transfection of LNCaP cells with TCTP siRNA caused time-dependent apoptosis of these cells (Fig. 4). Apoptosis was undetectable in control siRNA transfected cells.

Caspase- 3 and caspase- 8 activity assay. Caspase- 3 and caspase- 8 are major death related enzymes that are up-regulated 
$24 \mathrm{~h}$
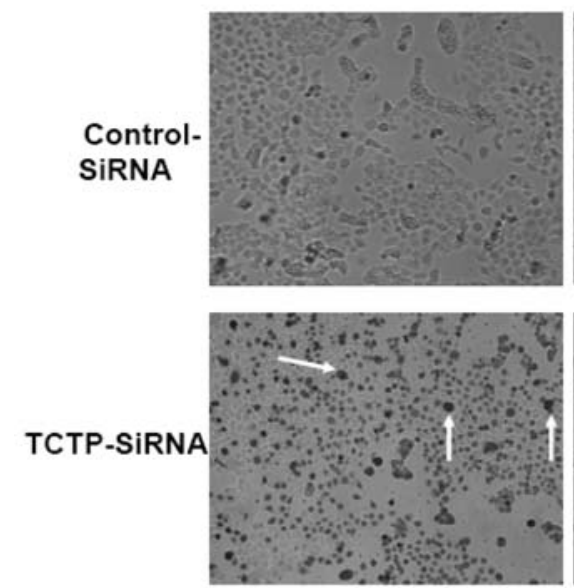

$48 \mathrm{~h}$
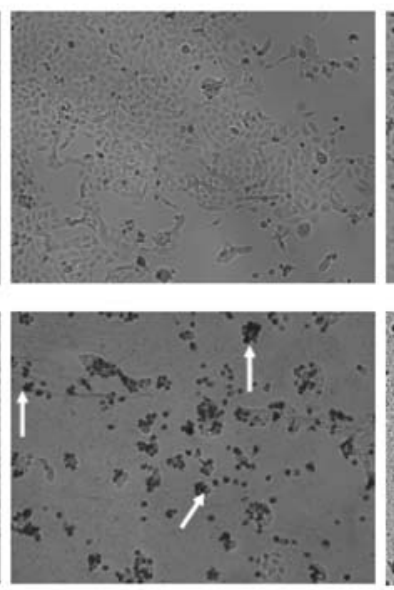

$72 \mathrm{~h}$
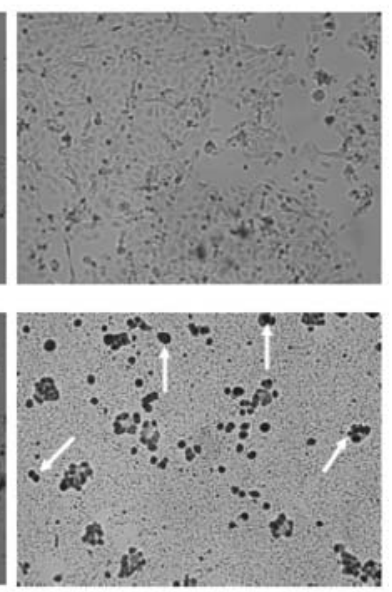

Figure 3. Trypan-blue staining of prostate cancer cells. The effects of TCTP siRNA on the viability of LNCaP cells were analyzed by trypan-blue staining. LNCaP cells $\left(10^{4}\right.$ cells $\left./ \mathrm{ml}\right)$ cultured in tissue culture slides were transfected with TCTP siRNA and the viability of the cells were analyzed by adding $100 \mu 1$ of trypan-blue dye to the cultures at various time-points. Light microscopy observations show that knock down of TCTP gene expression by siRNA significantly reduced the viability of prostate cancer cells by $72 \mathrm{~h}$ after siRNA transfection. Arrows indicate dead cells. Results shown are representative of one of four similar experiments.
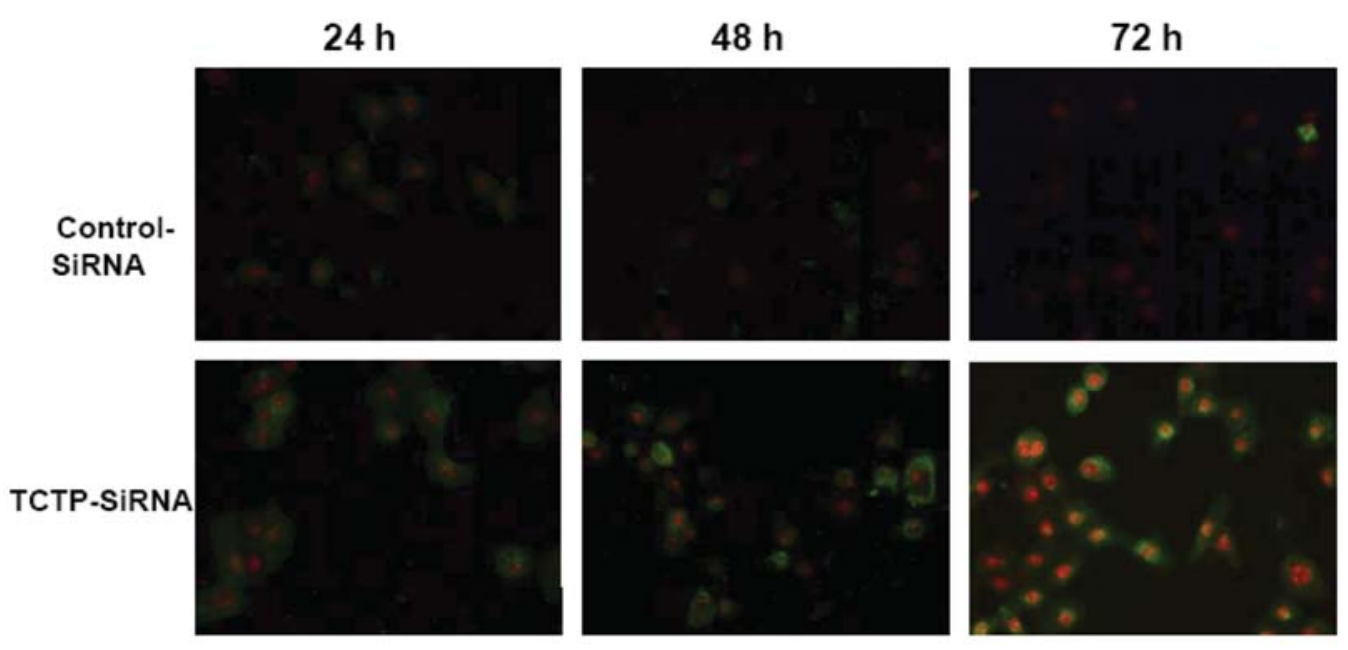

Figure 4. Annexin V-FITC detection of apoptosis in prostate cancer cells. LNCaP cells $\left(10^{4}\right.$ cells $\left./ \mathrm{ml}\right)$ were transfected with TCTP siRNA for $24 \mathrm{~h}, 48 \mathrm{~h}$ and $72 \mathrm{~h}$. Following transfection, cells were stained with Annexin V-FITC and propidium iodide. The cells were visualized under a fluorescence microscope. Results show that LNCaP cells transfected with TCTP siRNA undergo time-dependent apoptosis compared to cells transfected with control siRNA. Results presented are representative of one of three similar experiments.

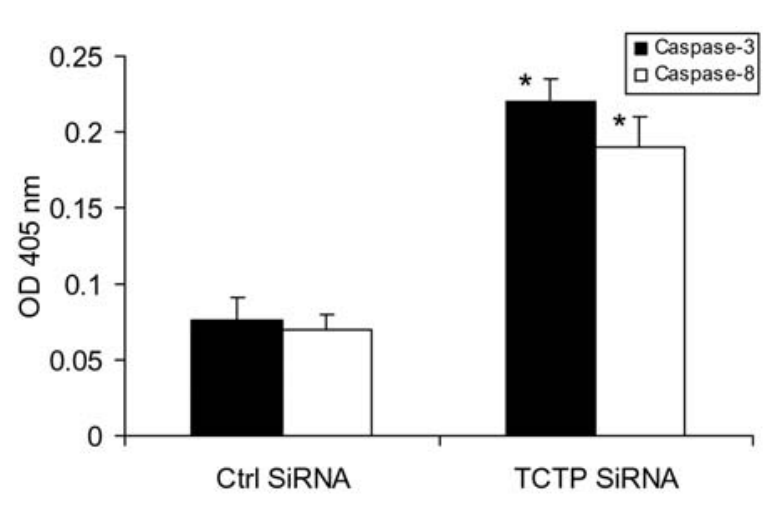

Figure 5. Detection of caspase activities in LNCaP cells transfected with TCTP siRNA. LNCaP cells were treated with TCTP siRNA for $72 \mathrm{~h}$, and $100 \mu \mathrm{g}$ of protein from each sample were analyzed for caspase-3 and caspase- 8 activities by colorimetric assay. These results showed that TCTP siRNA induced significant caspase-3 or caspase-8 activities in LNCaP cells. Data is representative of one of three similar experiments. when cells undergo apoptosis (24). To determine whether caspase- 3 and caspase- 8 enzymes are activated in TCTP siRNA transfected LNCaP cells, we used a chromogenic based caspase assay. Our results show that transfection with TCTP siRNA induced significant $(\mathrm{P}<0.05)$ activation of caspase-3 and caspase- 8 in LNCaP cells (Fig. 5) compared to control siRNA transfected cells.

\section{Discussion}

Results presented in this study indicate that gene silencing of TCTP by siRNA causes growth suppression and apoptosis of LNCaP cells. Androgen ablation therapy is the mainstay of prostate cancer treatment. However, within few years patients undergoing androgen ablation therapy develop hormoneindependent prostate cancer. Therefore, effective newer agents for the control of prostate cancer are necessary. TCTP 
is a growth associated protein (25), which plays a crucial role in the protein elongation step by interacting with eukaryotic elongation factor 1A (eEF1A) (26). Several pharmacological drugs including antihistaminics (7), S-trityl-L-cysteine (STLC) (27) and plasminogen activator inhibitor (PAI) (28) can decrease the expression of TCTP in cancer cells. This decreased expression of TCTP in cancer cells leads to apoptosis and tumor growth retardation $(4,7,29)$. Results of this study show therapeutic potential of siRNA targeting TCTP in LNCaP prostate cancer cells.

Our results showed that TCTP is highly expressed in LNCaP cells compared to normal prostate epithelial cells. This observation is consistent with previous reports in other cancer cells where TCTP was also found abundantly expressed $(4,5)$. Similarly TCTP is described as a growth related protein that promotes cell survival and growth. This might explain their higher expression in cancer cells. In fact, Li et al (4) were the first to demonstrate the anti-apoptotic property of TCTP. Subsequent studies from different laboratories confirmed TCTP as an important anti-apoptotic protein in the cell $(5,29,30)$. The role of TCTP in prostate cancer cells is not well understood. A recent study showed that somatostatin, a growth inhibitory hormone down-regulates the expression of TCTP in LNCaP cells (31). This suggested that manipulating the expression of TCTP can be a useful strategy to control the growth of LNCaP cells. To test this we silenced TCTP gene in LNCaP cells using an siRNA strategy. Our results confirmed that silencing TCTP gene by siRNA significantly decreased the viability of LNCaP cells in vitro reiterating its major role in cellular growth $(30,32)$.

Knock down of TCTP gene also resulted in increased cell death due to apoptosis in LNCaP cultures. These findings support the previous observation that TCTP is an anti-apoptotic protein and silencing the gene promoted apoptosis in these cell lines. Apoptosis is mediated by activation of various caspases, especially activation of caspase- 8 and caspase- 3 has a significant role. Our results showed that knock down of TCTP were associated with an increase in caspase- 8 and caspase- 3 activities in LNCaP cells. Caspase- 8 is the initiator caspase recruited by death receptors Fas, tumor necrosis factor receptor 1 (TNFR1) and TNF-related apoptosis inducing ligand (TRAIL) to mediate apoptosis (33). Recent studies showed that caspase- 8 can interact with androgen receptor and inhibit its transactivation (34). Since androgen receptor transactivation is important for LNCaP cell growth and proliferation, it is possible that caspase- 8 activation can adversely affect the cell viability and proliferation of $\mathrm{LNCaP}$ cells. Activation of caspase- 8 is known to trigger downstream caspases, most importantly caspase-3 that mediates cell death.

Our studies also showed that there was significant caspase-3 activity in LNCaP cells that are transfected with TCTP siRNA. A previous study showed that TCTP acts at the level of mitochondria by inserting into mitochondrial membrane preventing Bax dimerization (35). Dimerization of Bax results in loss of mitochondrion permeability, translocation of cytochrome c and activation of caspase-3 (36). Thus, in LNCaP cells, over-expression of TCTP might help block mitochondrial mediated apoptosis by interfering with the Bax dimerization. Thus, findings in this study showed that knock down of TCTP gene activates both upstream and downstream caspases resulting in apoptotic death of LNCaP cells. Unfortunately, LNCaP cells are resistant to certain therapeutically important drugs such as TRAIL $(37,38)$. LNCaP cells resistant to TRAIL are defective in activation of multiple caspases (39). Therefore, reagents such as TCTP siRNA as discussed in this study which activate multiple caspases might find use as an adjuvant or stand alone treatment at least for androgen-dependent prostate cancer.

The gene silencing effects of TCTP siRNA is not known in androgen-independent prostate cancer cells. Therefore, our future studies will evaluate the gene therapeutic potential of TCTP siRNA in androgen-independent prostate cancer cells such as DU145 and PC-3 cells. Further studies are also needed to elucidate the mechanism by which TCTP protects prostate cancer cells. Finally, several anti-apoptotic mechanisms have been proposed for TCTP $(35,40)$. Although, TCTP is the most abundantly expressed calcium binding protein in prostate cancer (6), its role in prostate tumorigenesis is not fully known at this time. Additional studies are in progress in our laboratory to elucidate the TCTP antiapoptotic mechanism as well as the siRNA delivery route and its therapeutic potential against prostate cancer in animal models.

\section{Acknowledgements}

This study was supported by funding received from Excellence in Academic Medicine (EAM) award of Swedish American Health System to M.G.

\section{References}

1. Bohm H, Benndorf R, Gaestel M, Gross B, Nurnberg P, Kraft R, Otto A and Bielka H: The growth-related protein P23 of the Ehrlich ascites tumor: translational control, cloning and primary structure. Biochem Int 19: 277-286, 1989.

2. Bonnet C, Perret E, Dumont X, Picard A, Caput D and Lenaers G: Identification and transcription control of fission yeast genes repressed by an ammonium starvation growth arrest. Yeast 16: 23-33, 2000.

3. MacDonald SM, Rafnar T, Langdon $\mathrm{J}$ and Lichtenstein LM: Molecular identification of an IgE-dependent histaminereleasing factor. Science 269: 688-690, 1995.

4. Li F, Zhang D and Fujise K: Characterization of fortilin, a novel antiapoptotic protein. J Biol Chem 276: 47542-47549, 2001.

5. Tuynder M, Susini L, Prieur S, Besse S, Fiucci G, Amson R and Telerman A: Biological models and genes of tumor reversion: cellular reprogramming through tpt1/TCTP and SIAH-1. Proc Natl Acad Sci USA 99: 14976-14981, 2002.

6. Arcuri F, Papa S, Carducci A, Romagnoli R, Liberatori S, Riparbelli MG, Sanchez JC, Tosi P and del Vecchio MT: Translationally controlled tumor protein (TCTP) in the human prostate and prostate cancer cells: expression, distribution, and calcium binding activity. Prostate 60: 130-140, 2004.

7. Tuynder M, Fiucci G, Prieur S, Lespagnol A, Geant A, Beaucourt S, Duflaut D, Besse S, Susini L, Cavarelli J, Moras D, Amson R and Telerman A: Translationally controlled tumor protein is a target of tumor reversion. Proc Natl Acad Sci USA 101: 15364-15369, 2004.

8. Oikawa K, Ohbayashi T, Mimura J, Fujii-Kuriyama Y, Teshima S, Rokutan K, Mukai K and Kuroda M: Dioxin stimulates synthesis and secretion of IgE-dependent histamine-releasing factor. Biochem Biophys Res Commun 290: 984-987, 2002.

9. Sturzenbaum SR, Kille P and Morgan AJ: Identification of heavy metal induced changes in the expression patterns of the translationally controlled tumour protein (TCTP) in the earthworm Lumbricus rubellus1. Biochim Biophys Acta 1398: 294-304, 1998. 
10. Vercoutter-Edouart AS, Czeszak X, Crepin M, Lemoine J, Boilly B, Le Bourhis X, Peyrat JP and Hondermarck H Proteomic detection of changes in protein synthesis induced by fibroblast growth factor-2 in MCF-7 human breast cancer cells. Exp Cell Res 262: 59-68, 2001.

11. Baudet C, Perret E, Delpech B, Kaghad M, Brachet P, Wion D and Caput D: Differentially expressed genes in C6.9 glioma cells during vitamin D-induced cell death program. Cell Death Differ 5: 116-125, 1998

12. Gnanasekar M, Rao KV, Chen L, Narayanan RB, Geetha M, Scott AL, Ramaswamy K and Kaliraj P: Molecular characterization of a calcium binding translationally controlled tumor protein homologue from the filarial parasites Brugia malayi and Wuchereria bancrofti. Mol Biochem Parasitol 121: 107-118, 2002.

13. Rao KV, Chen L, Gnanasekar M and Ramaswamy K: Cloning and characterization of a calcium-binding, histamine-releasing protein from Schistosoma mansoni. J Biol Chem 277: 31207-31213, 2002.

14. Yarm FR: Plk phosphorylation regulates the microtubulestabilizing protein TCTP. Mol Cell Biol 22: 6209-6221, 2002.

15. Gachet Y, Tournier S, Lee M, Lazaris-Karatzas A, Poulton T and Bommer UA: The growth-related, translationally controlled protein P23 has properties of a tubulin binding protein and associates transiently with microtubules during the cell cycle. J Cell Sci 112: 1257-1271, 1999.

16. Saleem M, Adhami VM, Ahmad N, Gupta S and Mukhtar H: Prognostic significance of metastasis-associated protein S100A4 (Mts1) in prostate cancer progression and chemoprevention regimens in an autochthonous mouse model. Clin Cancer Res 11: 147-153, 2005.

17. Saleem M, Kweon MH, Johnson JJ, Adhami VM, Elcheva I, Khan N, Bin Hafeez B, Bhat KM, Sarfaraz S, Reagan-Shaw S, Spiegelman VS, Setaluri V and Mukhtar H: S100A4 accelerates tumorigenesis and invasion of human prostate cancer through the transcriptional regulation of matrix metalloproteinase 9. Proc Natl Acad Sci USA 103: 14825-14830, 2006.

18. Zhu N and Wang Z: Calreticulin expression is associated with androgen regulation of the sensitivity to calcium ionophoreinduced apoptosis in $\mathrm{LNCaP}$ prostate cancer cells. Cancer Res 59: 1896-1902, 1999.

19. Furuya Y, Lundmo P, Short AD, Gill DL and Isaacs JT: The role of calcium, $\mathrm{pH}$, and cell proliferation in the programmed (apoptotic) death of androgen-independent prostatic cancer cells induced by thapsigargin. Cancer Res 54: 6167-6175, 1994.

20. McConkey DJ and Orrenius S: The role of calcium in the regulation of apoptosis. Biochem Biophys Res Commun 239: 357-366, 1997

21. Taulli R, Accornero P, Follenzi A, Mangano T, Morotti A, Scuoppo C, Forni PE, Bersani F, Crepaldi T, Chiarle R, Naldini L and Ponzetto C: RNAi technology and lentiviral delivery as a powerful tool to suppress Tpr-Met-mediated tumorigenesis. Cancer Gene Ther 12: 456-463, 2005.

22. Yang Q, Fung KM, Day WV, Kropp BP and Lin HK: Androgen receptor signaling is required for androgen-sensitive human prostate cancer cell proliferation and survival. Cancer Cell Int 5: $8,2005$.

23. Zhang D, Li F, Weidner D, Mnjoyan ZH and Fujise K: Physical and functional interaction between myeloid cell leukemia 1 protein (MCL1) and Fortilin. The potential role of MCL1 as a fortilin chaperone. J Biol Chem 277: 37430-37438, 2002.

24. Yuan XJ and Whang YE: PTEN sensitizes prostate cancer cells to death receptor-mediated and drug-induced apoptosis through a FADD-dependent pathway. Oncogene 21: 319-327, 2002.

25. Bommer UA and Thiele BJ: The translationally controlled tumour protein (TCTP). Int J Biochem Cell Biol 36: 379-385, 2004.
26. Cans C, Passer BJ, Shalak V, Nancy-Portebois V, Crible V, Amzallag N, Allanic D, Tufino R, Argentini M, Moras D, Fiucci G, Goud B, Mirande M, Amson R and Telerman A: Translationally controlled tumor protein acts as a guanine nucleotide dissociation inhibitor on the translation elongation factor eEF1A. Proc Natl Acad Sci USA 100: 13892-13897, 2003.

27. Kozielski F, Skoufias DA, Indorato RL, Saoudi Y, Jungblut PR, Hustoft HK, Strozynski M and Thiede B: Proteome analysis of apoptosis signaling by S-trityl-L-cysteine, a potent reversible inhibitor of human mitotic kinesin Eg5. Proteomics 8: 289-300, 2008.

28. Jankun J, Aleem AM, Specht Z, Keck RW, LysiakSzydlowska W, Selman SH and Skrzypczak-Jankun E: PAI-1 induces cell detachment, downregulates nucleophosmin (B23) and fortilin (TCTP) in LnCAP prostate cancer cells. Int J Mol Med 20: 11-20, 2007.

29. Zhu WL, Cheng HX, Han N, Liu DL, Zhu WX, Fan BL and Duan FL: Messenger RNA expression of translationally controlled tumor protein (TCTP) in liver regeneration and cancer. Anticancer Res 28: 1575-1580, 2008.

30. Chen SH, Wu PS, Chou CH, Yan YT, Liu H, Weng SY and Yang-Yen HF: A knockout mouse approach reveals that TCTP functions as an essential factor for cell proliferation and survival in a tissue- or cell type-specific manner. Mol Biol Cell 18: 2525-2532, 2007.

31. Liu Z, Bengtsson S, Krogh M, Marquez M, Nilsson S, James P, Aliaya A and Holmberg AR: Somatostatin effects on the proteome of the LNCaP cell-line. Int J Oncol 30: 1173-1179, 2007.

32. Burgess A, Labbe JC, Vigneron S, Bonneaud N, Strub JM, van Dorsselaer A, Lorca T and Castro A: Chfr interacts and colocalizes with TCTP to the mitotic spindle. Oncogene (In press).

33. Thorburn A: Death receptor-induced cell killing. Cell Signal 16: 139-144, 2004.

34. Qi W, Wu H, Yang L, Boyd DD and Wang Z: A novel function of caspase- 8 in the regulation of androgen-receptor-driven gene expression. EMBO J 26: 65-75, 2007.

35. Susini L, Besse S, Duflaut D, Lespagnol A, Beekman C, Fiucci G, Atkinson AR, Busso D, Poussin P, Marine JC, Martinou JC, Cavarelli J, Moras D, Amson R and Telerman A: TCTP protects from apoptotic cell death by antagonizing bax function. Cell Death Differ 15: 1211-1220, 2008.

36. Lee DH, Szczepanski M and Lee YJ: Role of Bax in quercetininduced apoptosis in human prostate cancer cells. Biochem Pharmacol 75: 2345-2355, 2008.

37. Mitterberger M, Neuwirt H, Cavarretta IT, Hobisch A and Culig Z: Increased resistance to trail-induced apoptosis in prostate cancer cells selected in the presence of bicalutamide. Prostate 67: 1194-1201, 2007.

38. Munshi A, McDonnell TJ and Meyn RE: Chemotherapeutic agents enhance TRAIL-induced apoptosis in prostate cancer cells. Cancer Chemother Pharmacol 50: 46-52, 2002.

39. Rokhlin OW, Guseva NV, Tagiyev AF, Glover RA and Cohen MB: Caspase-8 activation is necessary but not sufficient for tumor necrosis factor-related apoptosis-inducing ligand (TRAIL)-mediated apoptosis in the prostatic carcinoma cell line LNCaP. Prostate 52: 1-11, 2002.

40. Graidist P, Yazawa M, Tonganunt M, Nakatomi A, Lin CC, Chang JY, Phongdara A and Fujise K: Fortilin binds $\mathrm{Ca}^{2+}$ and blocks $\mathrm{Ca}^{2+}$-dependent apoptosis in vivo. Biochem J 408: 181-191, 2007. 